\title{
Percepção e sensibilização ambiental de universitários sobre os impactos ambientais da disposição de resíduos solidos urbanos em Passo Fundo - RS
}

\section{Perception and sensitizing of students on the environmental impacts of disposal of urban solid waste in Passo Fundo - RS}

\begin{abstract}
RESUMO: O objetivo da pesquisa foi analisar a percepção ambiental de universitários e sensibilizar quanto aos impactos ambientais da disposição de resíduos sólidos urbanos (RSU) em um antigo local de disposição de resíduos de Passo Fundo, RS. Foram entrevistados universitários do curso de Arquitetura e Urbanismo e Engenharia Ambiental da UPF. Os acadêmicos não perceberam o impacto da disposição de RSU, devido à presença de vegetação na área, a qual traz a aparente visão de um ambiente recuperado. A sensibilização dos universitários foi desenvolvida com o entendimento de que a área ainda apresenta passivos ambientais e à saúde humana.
\end{abstract}

Palavras-chave: aterro sanitário; qualidade ambiental; educação ambiental.

\section{INTRODUÇÃO}

Os processos de degradação ambiental e a exploração descontrolada dos recursos e bens naturais resultaram na ameaça da economia e da qualidade de vida nas cidades. Desde a década de 70 até os tempos atuais, surgiram preocupações globais quanto aos inúmeros problemas decorrentes do desenvolvimento e do equilíbrio injusto entre as necessidades econômicas, sociais e ambientais das gerações presentes e futuras. Assim, advém a necessidade de ruptura desse paradigma, adotando uma nova forma de desenvolvimento, a qual está aliada ao equilíbrio ambiental. Essa idéia estabeleceu novas prioridades de ação, visando minimizar os impactos ambientais decorrentes das atividades humanas (SILVA e NETO, 2007; GONÇALVES, 2005).

Os resíduos sólidos urbanos gerados nas cidades têm sido motivos de preocupação nas ultimas décadas, pois tem causado crescente poluição e impactos sócio-ambientais devido à disposição final inadequada. Em lixões, os principais problemas provocados são: proliferação de vetores de doenças, geração de maus odores, poluição do solo e das águas subterrânea e superficial, pela infiltração do lixiviado resultante dos processos de decomposição dos RSU (SISINNO e MOREIRA, 1996; TRESSOLDI e CONSONI, 1998; TAKAYANAGUI, 2005).

Dessa maneira, a minimização, o aproveitamento e a reciclagem dos resíduos e subprodutos, a restauração de áreas degradadas e a preocupação com redução dos 
passivos são desafios constantes. Segundo Esqueda (2000), ações de educação ambiental inserem-se neste contexto, pois colaboram para a solução da problemática do lixo domiciliar através da construção de atitudes ambientalmente conscientes que estimulem a minimização da degradação, da contaminação humana e ambiental e da geração descontrolada de resíduos.

Segundo Santana (2008), as ações de educação ambiental podem funcionar como estratégias que visam envolver a população em torno da questão sócio-ambiental, de modo, a estimular mudança de conduta, reorientação de hábitos, atitudes e valores. Para o autor, a educação ambiental é "um processo no qual deve ocorrer o desenvolvimento progressivo de um senso de preocupação com o meio ambiente, baseado num completo $e$ sensível entendimento das relações do homem com o ambiente a sua volta levando-se em consideração a evolução histórica dessa relação".

O Ministério de Meio Ambiente (2009) define a educação ambiental como "um processo permanente, no qual os indivíduos e a comunidade tomam consciência do seu meio ambiente e adquirem conhecimentos, valores, habilidades, experiências e determinação que os tornam aptos de agir individual e coletivamente e resolver problemas ambientais presentes e futuros". Segundo Freitas e Ribeiro (2007), a educação ambiental surge como mecanismo para conscientizar o ser humano de que ele não é o centro do ambiente, mas faz parte e depende dele. Pádua (1997) explica que a "educação ambiental é a aprendizagem de como gerenciar e melhorar as relações entre a sociedade humana e o ambiente".

A educação ambiental é de fundamental importância para promover a mudança de paradigmas da população e a conservação da natureza. A educação ambiental pode ser trabalhada dentro de vários projetos e disciplinas, pois segundo Müller (1999) fazer educação ambiental é também revelar os interesses de diversos grupos sociais em jogo nos problemas ambientais. Além do amor à natureza e do conhecimento de seus mecanismos, é preciso aprender a consolidar os ideais com relação aos destinos da sociedade e do planeta.

Segundo Santos et al. (2007) o ensino da ciência tem como meta a formação da cidadania. O ensino deve proporcionar atividades contextualizadas, abordando vários conteúdos disciplinares para que os alunos entendam as relações entre ciência, tecnologia e sociedade. Além disso, a forma de ensino deve desenvolver o espírito crítico e de tomada de decisões. Dessa forma foi realizada a avaliação dos resíduos, no lixão do município de Cuité, PB, com alunos do ensino médio, estudando o descarte dos resíduos e propondo medidas técnicas corretas e seguras para o gerenciamento. O estudo contribuiu na formação de agentes detentores de opinião dentro da comunidade e multiplicadores de atitudes ambientalmente corretas.

Nos estudos de Furiam e Günther (2006), a educação ambiental serviu como ferramenta para o gerenciamento dos resíduos sólidos produzidos no campus da Universidade Federal de Feira de Santana. Os objetivos da educação ambiental foram os de levar à comunidade informações que estimulem a tomada de consciência, e ao desenvolvimento de atitudes e comportamentos que possam contribuir de forma ativa no entorno. Segundo Furiam e Günther (2006, p. 9), "as atitudes ambientais dos seres humanos em relação a essa, devem refletir sobre assuntos que vão além do ato de separar resíduos. É um profundo exercício crítico acerca dos valores que intervêm como suporte em sua ação".

Em comunidades afetadas pela disposição inadequada de resíduos sólidos urbanos, a avaliação da percepção ambiental da população é uma estratégia importante para avaliar o comportamento sócio-ambiental da população, bem como realizar ações de sensibilização e conscientização ambiental (NORONHA, 2007). Essa é uma forma de aplicar a educação ambiental de forma sensibilizadora, pois, segundo Faggionato (2008), o estudo da percepção auxilia na compreensão da relação do homem e o meio-ambiente 
e, portanto, é capaz de modificar o pensar e promover atitudes e condutas que despertem a preocupação ambiental.

Segundo Faggionato (2008), a percepção ambiental de cada indivíduo difere, bem como as respostas e as manifestações. Noronha (2007) afirma que a percepção ambiental pode atribuir valor ao ambiente e desta maneira sensibilizar o indivíduo que a sobrevivência humana está relacionada com a forma de utilização e conservação dos recursos naturais. Além disso, segundo Maia et al. (2007), o estudo da percepção ambiental permite uma escuta de valores, pensamentos, opiniões, sentimentos, necessidades e expectativas das comunidades de modo a auxiliar na tomada de decisões, desenvolver atitudes reativas e preventivas e promover ações de conscientização e sensibilização ambiental.

Mellazo (2005) explica que a percepção ambiental é "fundamental para compreender melhor as inter-relações entre o homem e o ambiente no qual vive, suas expectativas, satisfações e insatisfações, valores e condutas, como cada indivíduo percebe, reage, e responde diferentemente frente às ações do meio". Segundo Mellazo (2005) o estudo da percepção não busca apenas entender o que o individuo percebe, mas busca promover a sensibilização e a consciência do ambiente ao seu redor. Com a percepção e o engajamento do cidadão em relação à conservação aos bens naturais busca-se contemplar os objetivos da educação ambiental.

A pesquisa objetiva analisar a percepção ambiental de universitários e sensibilizar quanto aos impactos ambientais da disposição de resíduos sólidos urbanos na área denominada "Aterro Invernadinha", que serviu como local de disposição de resíduos sólidos urbanos no município de Passo Fundo, RS.

\section{METODOLOGIA}

\section{Local de Estudo}

A área de estudo é um antigo local de disposição de resíduos sólidos urbanos do município de Passo Fundo, RS. Esta área, conhecida como "Invernadinha", serviu por três décadas como local de disposição de resíduos urbanos. O aterro está desativado e transformado em uma área de estudos de recuperação ambiental, monitoramento e educação ambiental. O aterro "Invernadinha" situa-se junto a BR-285, entre o Campus da Universidade de Passo Fundo e a Embrapa - Trigo, com área correspondente a 50.985,67 $\mathrm{m} 2$.

A figura 1 apresenta a localização da área no município de Passo Fundo e a figura 2 uma visão de satélite da área.

\section{Análise da percepção ambiental}

Desde o ano de 2001 vêm sendo realizados estudos da área possibilitando a elaboração de diagnósticos de contaminação e monitoramento da recuperação natural.

A Análise da Percepção ambiental foi realizada em 2005 e 2008. O instrumento de análise foi entrevista com universitários do curso de Arquitetura e Urbanismo da Universidade de Passo Fundo (sexto e sétimo nível) e Engenharia Ambiental (primeiro nível), apresentando fotografias da área de estudo, questionando quanto à percepção e sensibilizando sobre os impactos da disposição de resíduos sólidos urbanos e importância para a saúde pública.

O questionário aplicado aos alunos foi:

a) A paisagem poderia ser há 15 anos atrás uma área de: 1. Lavoura; 2. 


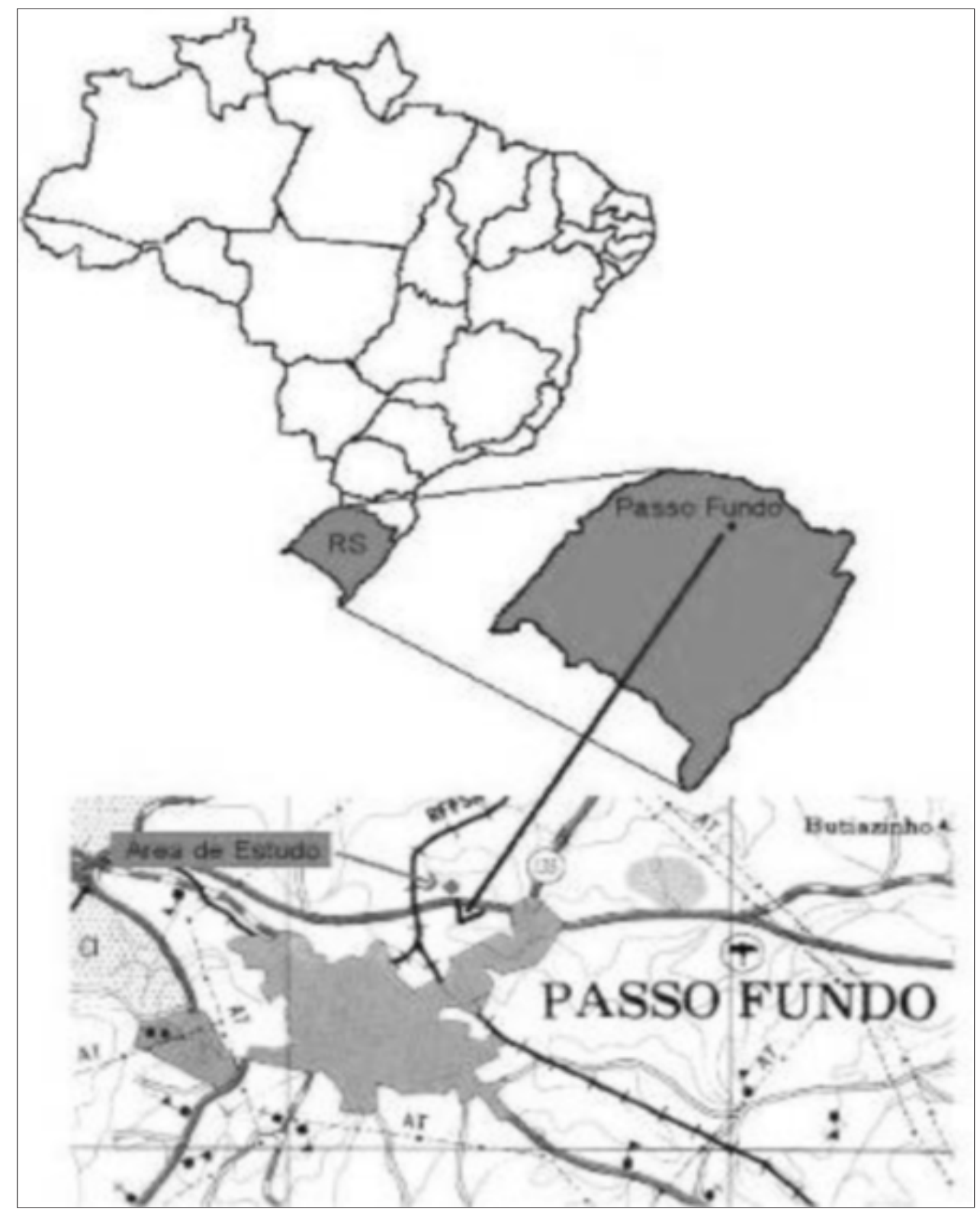

Figura 1 - Localização da antiga área de disposição de RSU em Passo Fundo, RS (sem escala)

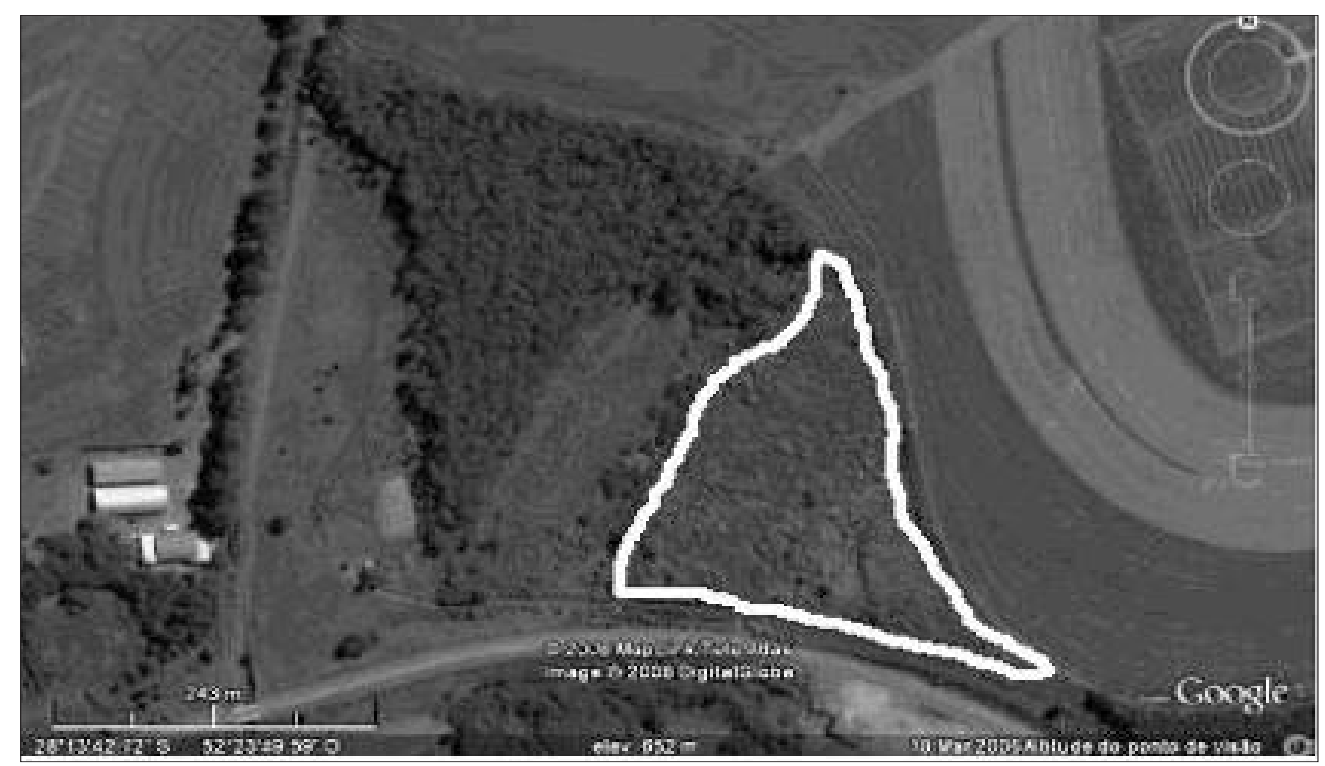

Fonte: Mapa Link/Tele atlas (2008).

Figura 2 - Vista de satélite do local de estudo 
Disposição de resíduos sólidos urbanos; 3. Campo; 4; Área de empréstimo de solo; 5. Floresta degradada.

As figuras 3 e 4 foram objetos da entrevista com os alunos. As figuras apresentam uma visão geral da área de estudo e do entorno, apresentando a cobertura da área com vegetação herbácea, arbustiva e arbórea, em 2000 e em 2005, respectivamente.

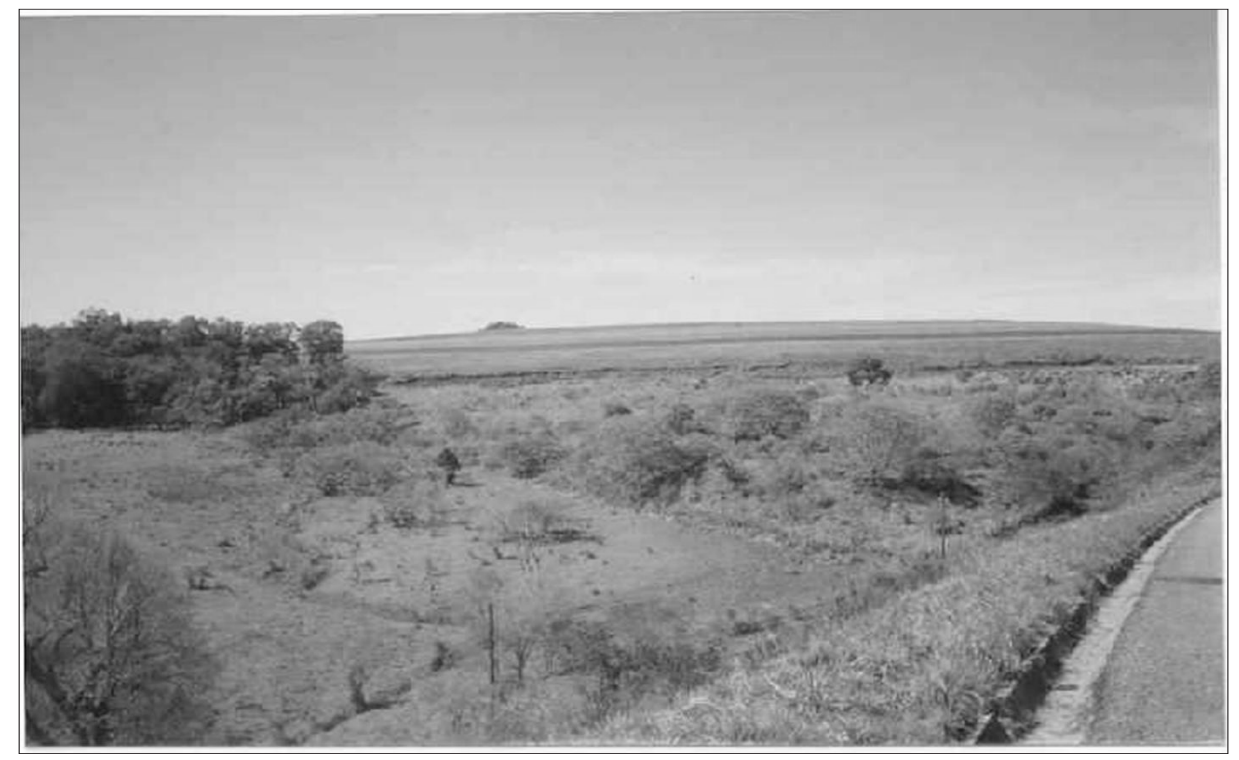

Figura 3 - Paisagem da área de estudo em 2000

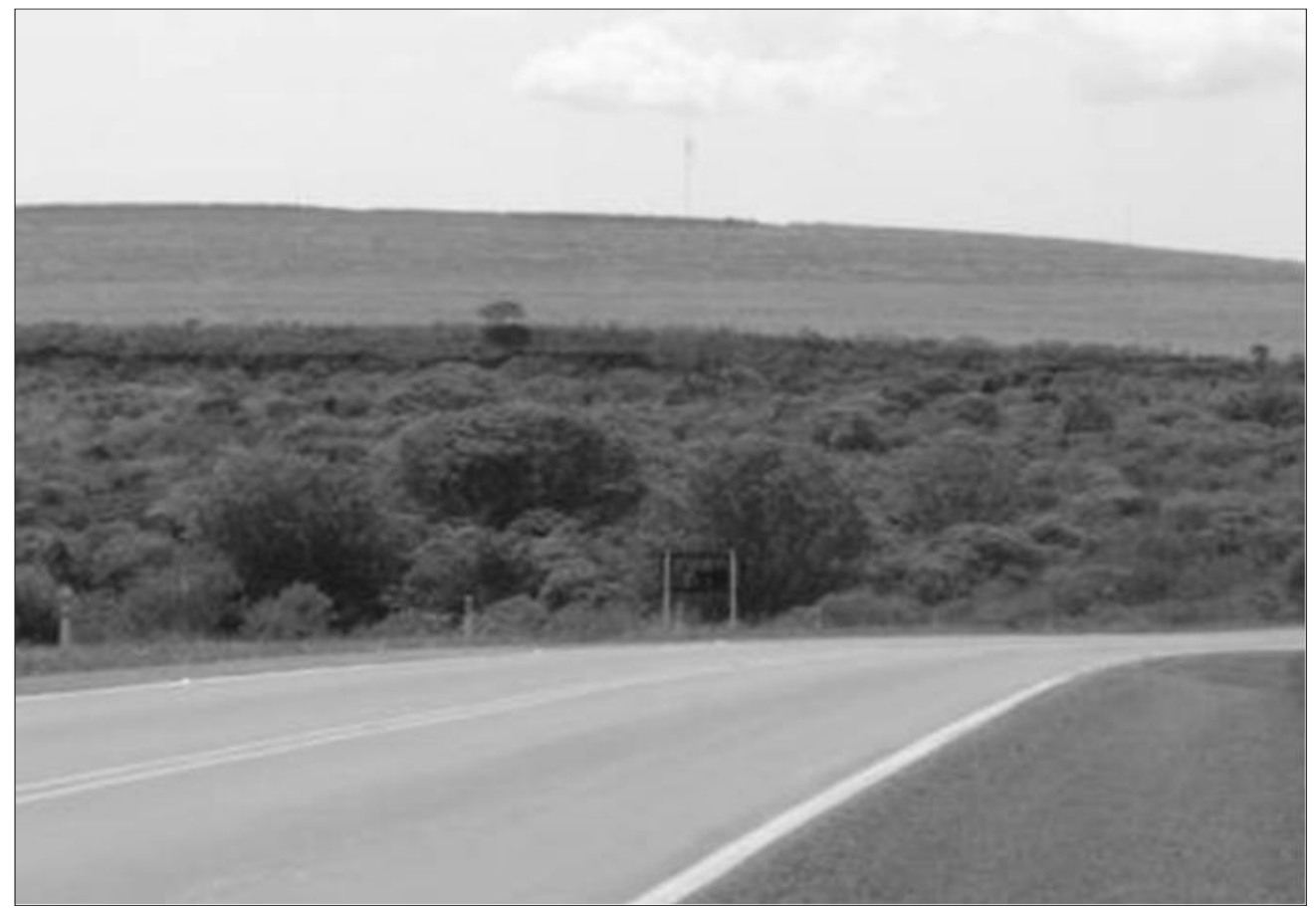

Figura 4 - Paisagem da área de estudo em 2005

\section{RESULTADOS E DISCUSSÕES}

A área apresenta indícios de recuperação natural com diferenças marcantes na presença da vegetação herbácea e arbórea. Os levantamentos da vegetação foram realizados por Melo (2000), verificando que o "lixão" abandonado após alguns anos apresenta desenvolvimento espontâneo das espécies provenientes da dispersão natural de sementes na área que estava desprovida de cobertura vegetal. Após cinco anos a paisagem deixou de ter impacto visual desagradável e vem sendo avaliada. 
Nas Figuras 5 e 6 apresenta-se a análise da percepção realizada no curso de Arquitetura e Urbanismo, em 2005 e 2008, respectivamente. A Figura 7 apresenta a análise da percepção realizada em 2008 no curso de Engenharia Ambiental.

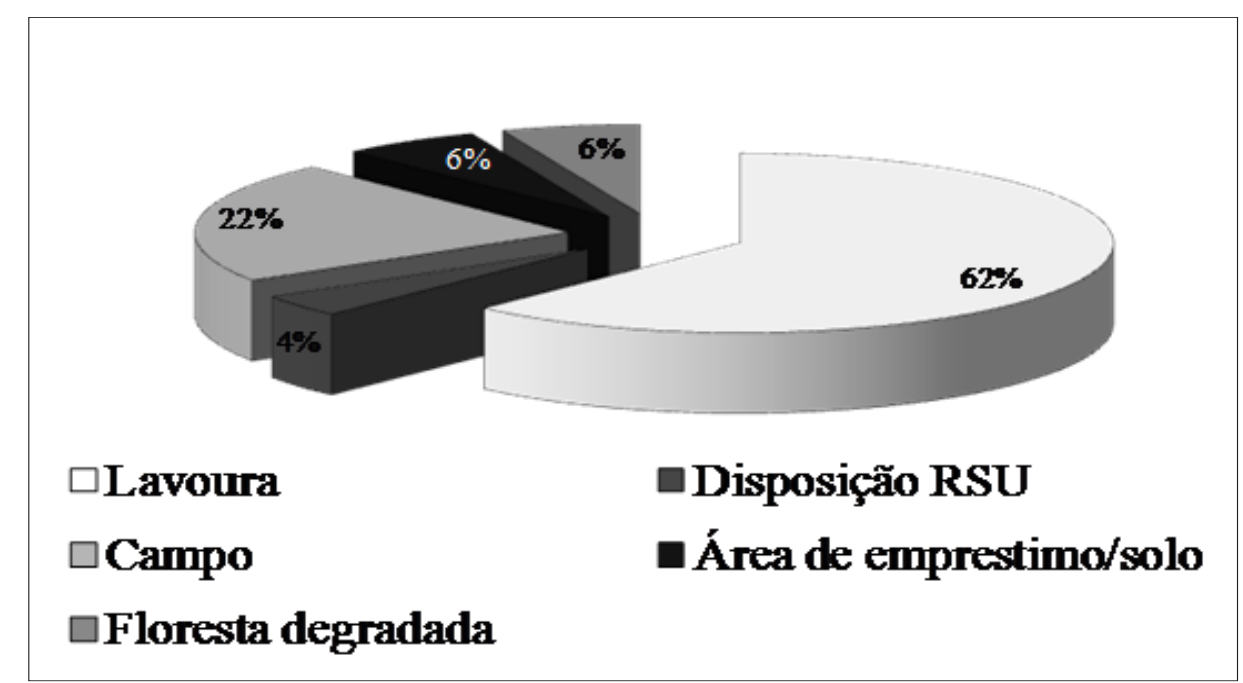

Figura 5 - Análise da percepção da paisagem há 15 anos atrás em 2005, para o curso de Arquitetura e Urbanismo

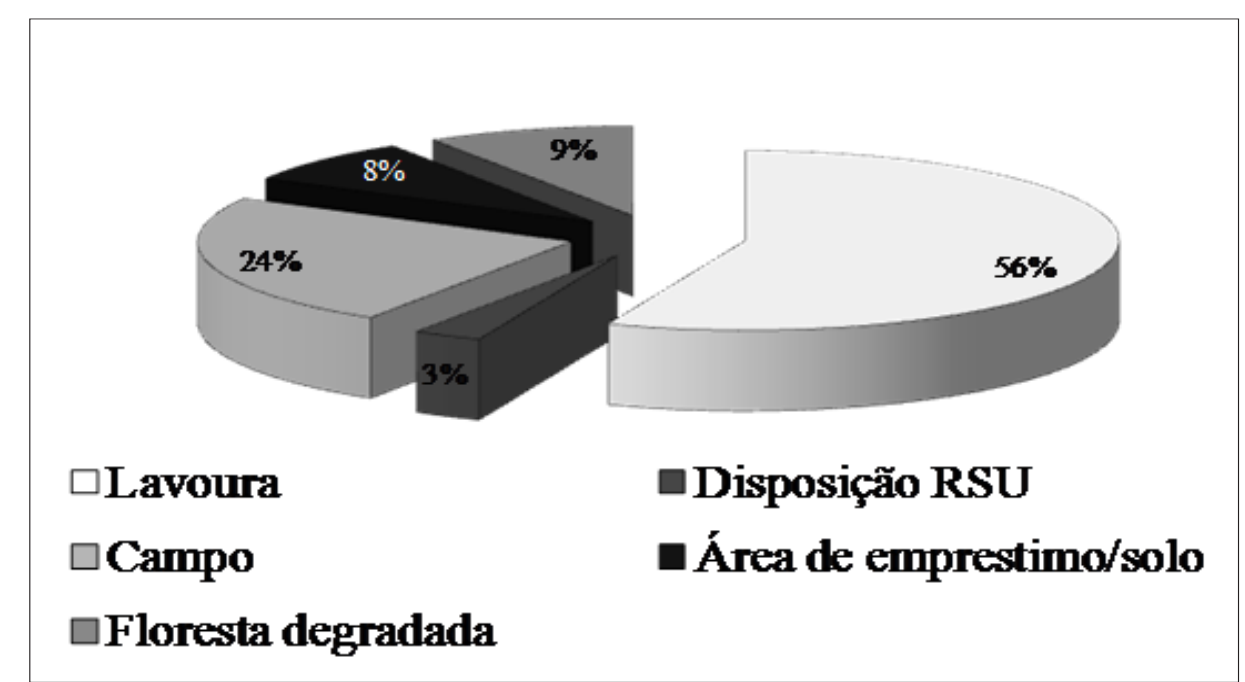

Figura 6 - Análise da percepção da paisagem há 15 anos atrás em 2008, para o curso de Arquitetura e Urbanismo

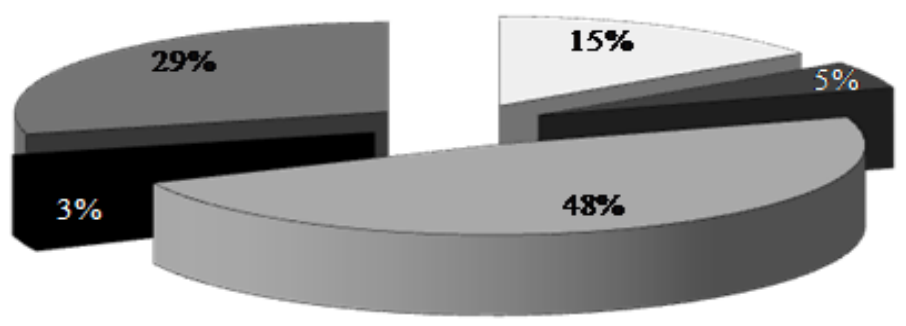

$\square$ Lavoura

$\square$ Campo
Disposição RSU

- Área de emprestimo/solo

\section{$\square$ Floresta degradada}

Figura 7 - Análise da percepção da paisagem há 15 anos atrás em 2008, para o curso de Engenharia Ambiental 
A análise da figura 5, para o curso de arquitetura e urbanismo em 2005, permitiu verificar que $62 \%$ consideraram a paisagem como uma área de lavoura abandonada, enquanto que apenas $4 \%$ sugeriram ser uma área de disposição de resíduos sólidos em função do tema abordado na pesquisa. Nesta mesma análise, os acadêmicos foram questionados se as imagens tratavam-se da mesma área. O resultado foi que $90 \%$ dos questionados não identificaram as duas paisagens como sendo da mesma área, em períodos distintos e apenas $10 \%$ perceberam tratar-se da mesma área. Já para o ano de 2008 (figura 6) os acadêmicos de arquitetura e urbanismo demonstraram que $56 \%$ consideravam a paisagem com lavoura abandonada e $3 \%$ consideravam a área como de disposição de resíduos sólidos.

Para os acadêmicos de Engenharia Ambiental, avaliados em 2008 (figura 7), 48 \% consideraram a paisagem como uma área campo, $29 \%$ de floresta degradada e apenas $5 \%$ sugeriram ser uma área de disposição de resíduos sólidos. Em comparação com os dados da entrevista realizada com os alunos do curso de Arquitetura e Urbanismo, houve uma diferença de percepção dos universitários, mas isso não refletiu para identificar a área como de disposição de resíduos sólidos, o que concorda com Mellazo (2005) e Faggionato (2008), quanto à percepção dos indivíduos em relação ao ambiente e como se pode integrá-los no sistema.

Noronha (2007) argumenta que cada forma de percepção pode atribuir valor ao ambiente e contribuir para sensibilizar o indivíduo quanto à forma de utilização e conservação dos recursos naturais. Da mesma maneira, a avaliação da percepção de uma comunidade vem ao encontro do auxílio na tomada de decisões, pois funciona como indicativo quanto aos impactos prioritários e orienta quanto às necessidades de intervenção para recuperação e conservação dos recursos naturais envolvidos.

A análise da percepção apresentou evidência de recuperação natural da área, pois os universitários não observaram a existência anterior do passivo. A presença da vegetação transformou a área, minimizando o impacto visual, permitindo a inter-relação do ambiente natural com a área degradada e integrando-a na paisagem regional. Entretanto, foi necessário o entendimento que a área ainda apresenta os passivos ambientais como poluição do solo, mananciais hídricos, alterações nos ecossistemas e problemas à saúde humana como contaminação aos seres vivos e proliferação de vetores de doenças.

A avaliação da percepção ambiental contribui da mesma maneira como indicativo das deficiências observadas no sistema educacional e falta de conhecimento ambiental da sociedade, segundo Carolino e Pasqual (2004). Um estudo de percepção realizado pelos mesmos autores com estudantes do ensino médio e fundamental revelou desconhecimento sobre os problemas ambientais, bem como da importância dos recursos naturais para os seres vivos. Diante do conhecimento dessas falhas pode-se interferir nas práticas de educação e conscientização ambiental enfatizando as principais deficiências. Além disso, segundo Fernandes et al. (2008), um banco de dados sobre a percepção da população pode auxiliar na intervenção por meio de ações preventivas e corretivas, através de programas de educação ambiental. Oliveira e Corona (2008) salientam que esses estudos podem indicar pontos chaves em que a prática da educação ambiental poderá sensibilizar, conscientizar e trabalhar de forma conjunta as dúvidas que os sujeitos tem quando forem questionados e lhes forem apresentadas as questões ambientais.

Estudos de percepção ambiental realizados por Mello (2005) relacionados com o programa de coleta seletiva em Salvador, Bahia, revelaram as deficiências do programa pelos baixos níveis de participação dos cidadãos envolvidos, devido à falta de divulgação, falta de cultura e percepção dos problemas envolvidos. Estimular a percepção ambiental quanto aos impactos sócio-ambientais conseqüentes é, neste caso, uma tarefa primordial e primária que desperta a sensibilização individual e estimula a conscientização, estando aliada ao bom andamento de programas de educação ambiental continuada. 
Nesse contexto, insere-se a educação ambiental, conforme apresentado por Faggionato (2008) e Noronha (2007), a qual favorece ações de sensibilização quanto aos problemas ainda existentes e estimula mudança de atitudes e condutas a favor da preservação dos recursos naturais e solução dos problemas à saúde humana, bem como promove o espírito questionador na busca de soluções ao problema dos resíduos sólidos. Após a avaliação da percepção dos estudantes, espera-se que eles tenham entendido que a fonte de contaminação pelos resíduos sólidos ainda permanece "camuflada" na área e que este ambiente ainda é uma fonte vulnerável de passivos ambientais, podendo proliferar vetores nocivos à saúde e contaminações aos seres vivos. Da mesma maneira, após discussão, houve ações de sensibilização e a conscientização ambiental quanto à prevenção da origem do problema e o combate aos passivos ainda existentes na sociedade.

AAgenda 21 estabelece que o manejo dos resíduos sólidos é uma questão importante para a qualidade do meio ambiente e deve ir além do simples depósito ou aproveitamento dos resíduos gerados, buscando resolver a causa do problema, mudando padrões de produção e consumo e integrando as diversas ações para o manejo dos resíduos municipais como a saúde ambiental e da comunidade antrópica (SATO e SANTOS, 1999). Considerando a afirmação, verificou-se que os universitários, quando questionados quanto à segregação de resíduos sólidos urbanos, 100 \% consideraram essencial para minimizar os impactos, enfatizando a importância da coleta seletiva dos resíduos e demonstrando a preocupação com as questões ambientais e de saúde antrópica.

Avaliando os resultados de Carolino e Pasqual (2004) e Mello (2005), que observaram total desconhecimento da comunidade envolvida quanto à importância do cuidado quanto aos resíduos sólidos, pode-se dizer que os universitários estudados nessa pesquisa apresentaram um comportamento que difere, pois já existe conhecimento do assunto. Em todo processo evolutivo de transformação é necessário ir além do conhecimento. Para atingir-se o objetivo da transformação de paradigmas e concretização da conscientização, é necessário, primeiro, que o conhecimento torne-se atitude que implicará em seguida em transformação da conduta individual e após na coletiva.

A sensibilização, inserindo os universitários no planejamento e ação prática, desperta maior interesse e responsabilidade, integrando-os nos problemas de sua comunidade e despertando a investigação para encontrar soluções para os mesmos, criando uma nova postura com cidadania que busca minimizar os impactos ambientais e à saúde. Segundo Noronha (2007), "um programa de educação ambiental somente se concretiza dentro de um processo de mudanças" e neste caso é necessário em primeiro lugar desenvolver atitudes sensibilizadoras. A educação ambiental, inserida neste contexto, constitui uma alternativa garantida a longo prazo para reverter os processos de destruição e descomprometimento público, pois transmite conhecimento, altera paradigmas, valores, atitudes e comportamentos, desperta orgulho e incentiva a participação em ações que contribuem para a proteção, conservação e exercício da cidadania com responsabilidade social, o que concorda com Furiam e Günther (2006), Maia et al. (2007), Santos et al. (2007) e Santana (2008).

\section{CONCLUSÕES}

A percepção ambiental dos universitários foi diferente em relação ao uso e interpretação da paisagem, porém não perceberam o impacto ambiental da disposição RSU, devido à presença de vegetação na área, a qual traz a aparente visão de um ambiente recuperado.

A sensibilização dos universitários, relacionada à área, foi norteada no contexto da ação mitigadora dos impactos ambientais, enfatizando a função de cada indivíduo na responsabilidade sócio-ambiental e minimização dos impactos no ambiente e na saúde humana devido às atividades antrópicas. A sociedade deve perceber que a área está em processo de recuperação ambiental, mas ainda apresenta os passivos ambientais, tais como: poluição do solo e mananciais hídricos, alterações nos ecossistemas, contaminação dos seres vivos e proliferação de vetores de doenças. 
Nesse sentido, são necessárias práticas de educação ambiental que incentivem o exercício da cidadania, o comprometimento da comunidade na segregação e reaproveitamento de resíduos e o gerenciamento integrado dos passivos no meio urbano. Acredita-se que, qualquer atividade envolvendo o estímulo a boas práticas, tanto na resolução do problema de resíduos sólidos com de saúde pública devem estar acompanhada de ações de educação ambiental, porém muito ainda necessita ser feito buscando atingir a conservação do meio ambiente, a garantia da saúde pública, a qualidade de vida e o bemestar da população.

\section{REFERÊNCIAS}

AGENDA21. Conferência das Nações Unidas sobre Meio Ambiente e Desenvolvimento. 3. ed. Brasília: Senado Federal, Subsecretaria de Edições, 2001.

CAROLINO, E. F.; PASQUAL, A. Resíduos sólidos urbanos e percepção ambiental de alunos do ensino fundamental e médio do município de Cerqueira César - SP. OLAM Ciência \& Tecnologia, v.4, n. 1, p. 679 - 689, abr. 2004.

ESQUEDA, M.D. Uma abordagem ambiental, energética e educacional da problemática do lixo domiciliar urbano. 2000. Originalmente apresentada como dissertação de mestrado em Agronomia / Área de Energia na Agricultura. Universidade Estadual Paulista - UNESP, 2000.

FAGGIONATO, Sandra. Percepção ambiental. Disponível em: <http://educar.sc.usp.br/ biologia/textos/m_a_txt4.html>. Acesso em: 19. jan. 2008.

FERNANDES, R. S.; et al. Avaliação da percepção ambiental da sociedade frente ao conhecimento da legislação ambiental básica. In: ENCONTRO LATINO AMERICANO DE UNIVERSIDADES SUSTENTÁVEIS, 1., 2008. I ELAUS: Universidades Sustentáveis, Possibilidades e Desafios. Passo Fundo: RS: UPF, 2008.

FREITAS, R.E.; RIBEIRO, K.C.C. Educação e percepção ambiental para a conservação do meio ambiente na cidade de Manaus uma análise dos processos educacionais no Centro Municipal de Educação Infantil Eliakin Rufino. Revista Eletrônica Aboré - Publicação da Escola Superior de Artes e Turismo Manaus, n. 3, nov. 2007. Disponível em: <http:// www.revista.uea.edu.br/abore/artigos/artigos_3/Rafael\%20Estrela\%20de\%20Freitas.pdf> Acesso em: 19 jan. 2009.

FURIAM, S. M.; GÜNTHER, W.R. Avaliação da educação ambiental no gerenciamento dos resíduos sólidos no campus da Universidade estadual de Feira de Santana. Sitientibus. n.35, p. 7-27, 2006. Disponível em: <http://www.ufpa.br/numa/especializ/ cursosespecializacao/2007/TEXTO2056.pdf>.Acesso em: 29 dez. 2007.

GONÇALVES, D. P. Desenvolvimento sustentável: o desafio da presente geração. Espaço Acadêmico. v. 51. Disponível em: <http://www.espacoacademico.com.br/051/51goncalves. htm>. Acesso em: 21 dez. 2009.

MAIA, F.; et al. A percepção ambiental dos professores da rede pública de Mato Castelhano/ RS sobre a floresta nacional de Passo Fundo. In: SIMPÓSIO GAÚCHO DE EDUCAÇÃO AMBIENTAL, 4., Anais do IV SIGEA... Erechim: URICER, 2007.

MAP LINK/TELE ATLAS: Imagem aérea do Google Earth. Google, 2005. Escalas variam.

MELLAZO, G.C. A percepção ambiental e educação ambiental: uma reflexão sobre as relações interpessoais e ambientais no espaço urbano. Olhares \& Trilhas. Uberlândia, Ano VI, n. 6, p. 45-51, 2005.

MELO, E.F.R.Q. Projeto de Recuperação Ambiental da Antiga Área de Disposição de Resíduos Sólidos Urbanos de Passo Fundo. 2000. Originalmente apresentada como monografia (Especialização em Engenharia Ambiental), Universidade de Passo Fundo, 2000. 
MELLO, R. M. Percepção ambiental da população do Alto Itaigara em relação à gestão dos resíduos sólidos - Programa de coleta seletiva/LIMPURB, Salvador - BA. 2005. Originalmente apresentada como monografia (Curso de Ciência Biológicas), Universidade Federal da Bahia, 2005.

MOTA, F. S. B. Conhecimento para promoção do Saneamento, Saúde e Ambiente. In: PHILIPPI JR., A. Saneamento, Saúde e Ambiente: fundamentos para o desenvolvimento sustentável. Barueri, SP: Manole, 2005. p. 809-832.

MINISTÉRIO DO MEIO AMBIENTE. Educação e Interpretação ambiental. Disponível em: < http://www.mma.gov.br/port/sbf/dap/educamb.html> . Acesso em: 19 jan. 2009.

MÜLLER, J. Educação ambiental: Diretrizes para a prática pedagógica. Porto Alegre: Cortez, 1999.

NORONHA, I. O. Percepção e Comportamento Sócio-ambiental: a problemática dos resíduos sólidos urbanos. Revista Acadêmica, n. 3, set/out/nov, 2007. Disponível em: < http://www.mg.senac.br/Revistasenac/edicoes/edicao3.htm> . Acesso em: 19 jan. 2009.

OLIVEIRA, K. A. de; CORONA, H. M. P. A percepção ambiental como ferramenta de propostas educativas e políticas ambientais. ANAP Brasil, n.1, p. 53-72, Jul. 2008.

PADUA, S. M. Conceitos para se fazer a educação ambiental. 2.ed. São Paulo: $A$ secretaria, 1997. $115 \mathrm{p}$.

SANTANA, A. C. Educação ambiental e as empresas: um caminho para a sustentabilidade. Educação ambiental em ação, n. 24, 2008. Disponível em: <http://www.revistaea.org/ artigo.php?idartigo=573\&class $=21>$. Acesso em: 19 jan. 2008 .

SANTOS, J. E. L.; SANTOS, E. S.; CONCEIÇÃO, M. M. D. Educação Ambiental: Avaliação dos resíduos do lixão do município de Cuité/PB. In: CONGRESSO NORTENORDESTE DE QUÍMICA, 1. ,2007, Natal: UFRN, 2007. Disponível em: <http://www.annq. org/congresso2007/trabalhos_apresentados/T85.pdf>. Acesso em: 29 dez. 2007.

SATO, M.; SANTOS, J.E. Agenda 21: em sinopse. São Carlos: EdUFSCar, 1999.

SILVA, G. J. A.; NETTO, L. R. G. Urbanismo e Sustentabilidade. Revista de Antropologia Urbana, v.4, n.5, 2007. Disponível em: < http://www.aguaforte.com/osurbanitas5/ Silva\&Garcia\%20Netto2007.html>. Acesso em: 19 jan. 2009.

SISINNO, C. L. S.; MOREIRA, J. C. Avaliação da contaminação e poluição ambiental na área de influência do aterro controlado do Morro do Céu, Niterói, Brasil. Caderno de Saúde Pública. Rio de Janeiro, v.12, n.4, p. 515-523, out. /dez. 1996.

TAKAYANAGUI, A. M. M. Gerenciamento de resíduos de serviço de saúde In: PHILIPPI JR., A. Saneamento, Saúde e Ambiente: Fundamentos para o desenvolvimento sustentável. Barueri - SP: Manole, 2005. p. 323-374.

TRESSOLDI, M.; CONSONI, A. J. Disposição de resíduos. In: OLIVEIRA, A. M. S.; BRITO, S. N. A. Geologia de engenharia. São Paulo: Associação Brasileira de Geologia de Engenharia, 1998. p. 343-360.

1 Dr. em Agronomia, Professora da Faculdade de Engenharia e Arquitetura, cursos de Engenharia Ambiental e Arquitetura e Urbanismo, Universidade de Passo Fundo, Passo Fundo - RS, Campus I, km 171, BR 285, CEP 99052-900, Tel.: (54) 33168201 - ramal 8655, Fax: (54) 33168211, email: <evanisa@upf.br>

2 Acadêmico do curso de Engenharia Ambiental, Faculdade de Engenharia e arquitetura, Universidade de Passo Fundo, Passo Fundo - RS, Campus I, km 171, BR 285, CEP $99052-$ 900, Tel.: (54) 33168217, Fax: (54) 33168211, email: <eduardokorf@gmail.com> 